\title{
The Prognostic Effect of Metastatic Lymph Node Ratio in Operated Gastric Cancer Patients
}

\author{
Serhat Tokgoz ${ }^{1}$ and Fatma Bugdayci Basal ${ }^{2}$ \\ ${ }^{1}$ Department of General Surgery, Yildirim Beyazit Diskapi Training and Research Hospital, Ankara, Turkey \\ ${ }^{2}$ Department of Medical Oncology, Dr. A.Y. Ankara Oncology Training and Research Hospital, Ankara, Turkey
}

\begin{abstract}
Objective: To assess the prognostic importance of metastatic lymph node ratio (MLNR) in operated gastric cancer patients.

Study Design: Observational study.

Place and Duration of Study: Health Sciences University, Yildirim Beyazit Diskapi Training and Research Hospital, Department of General Surgery, Ankara, Turkey, between January 2014 and March 2019.

Methodology: Initially, record of a total of 171 patients, operated for gastric cancer, were retrieved. Inclusion criteria involved having gastric adenocarcinoma, undergoing curative-intent surgery, absence of neoadjuvant chemotherapy, dissection of $\geq 15$ lymph nodes, negative surgical margins, and no mortality within the first 30 days after surgery. Thirty patients were excluded for various reasons. Thus, clinicopathological features and prognostic factors including MLNR on overall and disease-free survival (DFS) were evaluated for the remaining 141 patients.

Results: The median age of the 141 patients was 63 years (IQR: $54-72$ years). The median MLNR was 0.18 (IQR: $0-0.47$ ). The cut-off value with highest sensitivity and specificity was determined as 0.25 (area under the curve (AUC); $0.724, \mathrm{Cl} 95 \%$; $0.639-0.808, \mathrm{p}<0.001$ ) in ROC curve analysis. Multivariable Cox regression analysis showed MLNR and perineural invasion (PNI) as independent prognostic factors. Patients with MLNR $>0.25$ had a 2.39 -fold higher risk of disease progression, and 3.76-fold higher risk of shorter survival.

Conclusion: The study contributed to the literature that MLNR is practical and useful as an independent prognostic factor predicting survival even better than tumor/node/metastasis (TNM) staging system.
\end{abstract}

Key Words: Gastric cancer, Metastatic lymph node ratio, Prognostic factor, Surgery.

How to cite this article: Tokgoz S, Basal FB. The Prognostic Effect of Metastatic Lymph Node Ratio in Operated Gastric Cancer Patients. J Coll Physicians Surg Pak 2020; 30(10):1035-1040 .

\section{INTRODUCTION}

Gastric cancer is the 5th most common cancer in the world, and the third most common cause of cancer related death. ${ }^{1,2}$ Many gastric cancers are in the advanced stage when diagnosed, but still is amenable to treatment by radical gastrectomy with regional lymph node dissection. However, these patients have poor survival compared with early disease. ${ }^{1}$ Gastric cancer can be diagnosed at an early stage, even if there is no clinical finding, with the improvement of diagnostic techniques and implementation of intensive screening programmes. ${ }^{3}$ Surgery is the only proven curative treatment; nevertheless, locoregional recurrence and distant metastasis rates are high. ${ }^{4}$

Correspondence to: Dr. Fatma Bugdayci Basal, Department of Medical Oncology, Dr. A.Y. Ankara Oncology Training and Research Hospital, Ankara, Turkey E-mail:dr.fatmabb@gmail.com

Received: July 03, 2020; Revised: October 06, 2020; Accepted: October 06, 2020

DOI: https://doi.org/10.29271/jcpsp.2020.10.1035
There is no effective treatment in case of recurrence. Therefore, identifying prognostic and predictive markers would be helpful to evaluate the exact condition of the disease and to plan more effective treatment. ${ }^{5,6}$

Adequate staging is essential in predicting prognosis. Tumor invasion depth and nodal involvement are important prognostic markers in surgical candidates. ${ }^{4}$ TNM staging is the most commonly used prognostic factor in gastric cancer. ${ }^{7.9}$ Traditionally, TNM classification is used, based on the number of metastatic lymph nodes. ${ }^{10}$ Studies have shown that the classification, according to the number of lymph nodes, is more sensitive; and it has a superior prognostic value than the classification based on lymph node localization. ${ }^{9,11,12}$ In TNM classification, at least 15 lymph nodes have to be removed for accurate staging. ${ }^{9,13}$ However, this rate is seldom achieved. ${ }^{14}$

Lymph node-positive patients have a worse prognosis than negative patients. ${ }^{7}$ Despite intensive search for novel prognostic factors such as serum and histopathological markers or molecular information, TNM staging remains to be the most commonly used prognostic factor to date. ${ }^{7,15}$ On the other hand, Japanese Gastric Cancer Association (JGCA) prefers localisation 
for nodal staging. ${ }^{9,16}$ For correct nodal staging, sufficient number of dissected lymph nodes that is representative of geographic location are required. However fulfilling these two requirements, cause complexity and might lead to erroneous staging named stage shift. ${ }^{13}$ Several studies have shown that MLNR can be an excellent independent prognostic marker in both early and advanced gastric cancers. ${ }^{8,9,13}$

Metastatic lymph node ratio is calculated by dividing the number of metastatic lymph nodes to the number of dissected lymph nodes. This ratio is also known as lymph node density. ${ }^{7,17}$

Metastatic lymph node ratio varies between 0 and 1 . The more the number of metastatic lymph nodes, the higher the MLNR; and it is associated with a worse prognosis. ${ }^{1,7,18}$ Moreover, MLNR can prevent stage migration that is seen with TNM classification. $^{9}$

The aim of the present study was to assess the effect of the prognostic factors on overall and disease-free survival in D1 or D2 type lymph node dissection in gastric cancer patients with special emphasis on the prognostic value of MLNR.

\section{METHODOLOGY}

Patients with gastric cancer, who underwent gastric surgery between January 2014 and March 2019 at the Department of General Surgery Health Sciences University, Yildirim Beyazit Diskapi Training and Research Hospital were evaluated retrospectively. Inclusion criteria involved having gastric adenocarcinoma, undergoing surgery with a curative intent, absence of neoadjuvant chemotherapy, dissection of at least 15 lymph nodes, negative surgical margins, and no mortality within the first 30 days after surgery. Exclusion criteria included having a non-gastric adenocarcinoma or neuroendocrine differentiation, palliative surgery, having received neoadjuvant chemotherapy, dissection of less than 15 lymph nodes, positive surgical margins, and mortality within the first 30 days.

A total of 171 patients were detected during initial screening. Thirty patients were excluded based on inclusion and exclusion criteria. Finally, 141 patients, who were operated with a curative intent, were included in the analyses. Patient charts and electronic records were used to collect study data including age, gender, tumor localisation, histological subtype, degree of differentiation, TNM stage, presence of lymphovascular invasion (LVI), perineural invasion (PNI), MLNR, type of gastric surgery and lymph node dissection, and presence of adjuvant chemoradiotherapy. Follow-up data, including time of death and disease progression, were retrieved from outpatient hospital database.

All patients included in the study had undergone D1 or D2 type lymph node dissection. MLNR was calculated by the ratio of the number of metastatic lymph nodes to the total number of dissected lymph nodes. This ratio varies between 0 and 1 .

Data were presented as median (IQR), number and percentage. In the survival analysis, DFS was defined as the time between the operation date and the first progression date. Overall survival (OS) was accepted as the period between the date of operation and the date of exitus or last follow-up date for surviving patients. In addition, the follow-up period was defined between the date of diagnosis and the last control date.

Survival rates were calculated by the Kaplan-Meier method. The univariate analyses were performed using log-rank test. In the multivariate analysis, independent factors predicting survival were analysed by using Cox regression analysis with the backward selection. Results were evaluated in a 95\% confidence interval and $p<0.05$ was found to be a significance level.

The absolute cut-off value of MLNR in predicting disease progression was analysed by the receiveroperating characteristics (ROC) curve analysis. According to the analysis, the cases with a sensitivity and specificity limit of less than $5 \%$ of the type 1 error in the evaluation of the area under the curve were interpreted to be statistically significant.

Statistical analysis was performed using SPSS (Statistical Package for Social Sciences for Windows) version18.0.

\section{RESULTS}

The median age of the 141 patients was 63 years (IQR: $54-72$ years). Males comprised $71.6 \%(n=101)$ of the study population. Adenocarcinoma was located in cardia in 48 (34.0\%) patients, in gastroesophageal junction in 46 (32.6\%), in corpus in $35(24.8 \%)$, and in antrum in 12 (8.5\%) patients. Regarding differentiation, 7 (5.0\%) patients had well differentiated tumor, 45 (31.9\%) had moderately differentiated, and 89 (63.1\%) had poorly differentiated tumor. Lymphovascular invasion was present in 76 patients (53.9\%); whereas, PNI was positive in 77 patients (54.6\%). Subtotal gastrectomy was performed in 22 (15.6\%) patients, and total gastrectomy was performed in 119 (84.4\%) patients. Table I states demographic and clinicopathological features of the whole study population.

The median number of extracted lymph nodes was 28 (IQR: 20 $38)$, the median number of metastatic lymph nodes was 6 (IQR: 0 - 12), and the median MLNR was 0.18 (IQR: 0 - 0.47). The cutoff value with highest sensitivity and specificity was determined as 0.25 (area under the curve (AUC); 0.724, $\mathrm{Cl} 95 \%$; $0.639-0.808, p<0.001$ ) in ROC curve analysis. The patients performed D2 dissection were not received adjuvant chemoradiotherapy.

In a median of 15.3 months (IQR: 8.0-32.8) follow-up duration; median DFS was 19.7 months (95\% Cl: 13.1-26.4), and median OS was 25.1 months ( $95 \% \mathrm{Cl}$ : 13.5-36.8, Figures 1 -a and b). Due to small sample sizes, when each parameter was taken alone, some parameters were grouped as follows: Age was categorised as $\leq 60$ and $>60$ years, type of differentiation (poorly differentiated and not poorly differentiated), stage (early stage I-II and advanced stage III a-b-c), and receiving adjuvant therapy or not. Initially, a univariate regression analysis was performed to determine the independent predictors of OS and DFS. While age seemed to be a significant predictor of reduced OS, gender had no effect neitherfor OS nor DFS. 
Table I: Clinicopathological characteristics of patients.

\begin{tabular}{|c|c|c|}
\hline Patient characteristics & Number (N) & Percent (\%) \\
\hline $\begin{array}{l}\text { Gender: } \\
\text { Female / male }\end{array}$ & $40 / 101$ & $28.4 / 71.6$ \\
\hline $\begin{array}{l}\text { Age: } \\
\leq 60 />60\end{array}$ & $60 / 81$ & $42.6 / 57.4$ \\
\hline $\begin{array}{l}\text { Location: } \\
\text { Cardia } \\
\text { Gastroesophageal junction } \\
\text { Corpus } \\
\text { Antrum }\end{array}$ & $\begin{array}{l}48 \\
46 \\
35 \\
12\end{array}$ & $\begin{array}{l}34.0 \\
32.6 \\
24.8 \\
8.5\end{array}$ \\
\hline $\begin{array}{l}\text { Adenocarcinoma subtype: } \\
\text { Rignet cell } \\
\text { Mucinous } \\
\text { Diffuse } \\
\text { Classic }\end{array}$ & $\begin{array}{l}35 \\
13 \\
3 \\
90\end{array}$ & $\begin{array}{l}24.8 \\
9.2 \\
2.1 \\
63.8\end{array}$ \\
\hline $\begin{array}{l}\text { Differentiation: } \\
\text { Poor } \\
\text { Moderate } \\
\text { Well }\end{array}$ & $\begin{array}{l}89 \\
45 \\
7\end{array}$ & $\begin{array}{l}63.1 \\
31.9 \\
5.0\end{array}$ \\
\hline $\begin{array}{l}\text { Lymphovascular invasion: } \\
\text { Positive } \\
\text { Negative }\end{array}$ & $\begin{array}{l}76 \\
65\end{array}$ & $\begin{array}{l}53.9 \\
46.1\end{array}$ \\
\hline $\begin{array}{l}\text { Perineural invasion: } \\
\text { Positive } \\
\text { Negative }\end{array}$ & $\begin{array}{l}77 \\
64\end{array}$ & $\begin{array}{l}54.6 \\
45.4\end{array}$ \\
\hline $\begin{array}{l}\text { Operation: } \\
\text { Subtotal gastrectomy } \\
\text { Total gastrectomy }\end{array}$ & $\begin{array}{l}22 \\
119\end{array}$ & $\begin{array}{l}15.6 \\
84.4\end{array}$ \\
\hline $\begin{array}{l}\text { Dissection type: } \\
\text { D1 } \\
\text { D2 }\end{array}$ & $\begin{array}{l}9 \\
132\end{array}$ & $\begin{array}{l}6.4 \\
93.6\end{array}$ \\
\hline $\begin{array}{l}\text { Adjuvant chemotherapy: } \\
\text { Received } \\
\text { Non-received }\end{array}$ & $\begin{array}{l}108 \\
33\end{array}$ & $\begin{array}{l}76.6 \\
23.4\end{array}$ \\
\hline $\begin{array}{l}\text { Adjuvant chemoradiotherapy: } \\
\text { Received } \\
\text { Non-received }\end{array}$ & $\begin{array}{l}64 \\
77\end{array}$ & $\begin{array}{l}45.4 \\
54.6\end{array}$ \\
\hline $\begin{array}{l}\text { Metastatic lymph node ratio: } \\
\leq 0.25 \\
>0.25\end{array}$ & $\begin{array}{l}85 \\
56\end{array}$ & $\begin{array}{l}60.3 \\
39.7\end{array}$ \\
\hline $\begin{array}{l}\text { Tumor: } \\
\text { T1a } \\
\text { T1b } \\
\text { T2 } \\
\text { T3 } \\
\text { T4a } \\
\text { T4b }\end{array}$ & $\begin{array}{l}4 \\
9 \\
20 \\
39 \\
66 \\
3\end{array}$ & $\begin{array}{l}2.8 \\
6.4 \\
14.2 \\
27.7 \\
46.8 \\
2.1\end{array}$ \\
\hline $\begin{array}{l}\text { Node: } \\
\text { N0 } \\
\text { N1 } \\
\text { N2 } \\
\text { N3a } \\
\text { N3b }\end{array}$ & $\begin{array}{l}37 \\
14 \\
24 \\
33 \\
33\end{array}$ & $\begin{array}{l}26.2 \\
9.9 \\
17.0 \\
23.4 \\
23.4\end{array}$ \\
\hline $\begin{array}{l}\text { Stage: } \\
\text { la } \\
\text { Ib } \\
\text { Ila } \\
\text { Ilb } \\
\text { Illa } \\
\text { Illb } \\
\text { Illc }\end{array}$ & $\begin{array}{l}9 \\
14 \\
16 \\
9 \\
15 \\
30 \\
48\end{array}$ & $\begin{array}{l}6.4 \\
9.9 \\
11.3 \\
6.4 \\
10.6 \\
21.3 \\
34.0\end{array}$ \\
\hline
\end{tabular}

Since the number of patients, who underwent total and subtotal gastrectomy was quite different, the type of operation was not evaluated in the univariate analyses due to imbalance of the patient numbers.
Univariate analysis results showed that the type of differentiation and presence of adjuvant therapy did not affect DFS and OS. However, according to TNM staging, presence of an advanced stage was significantly reduced DFS and OS compared with early stage. In addition, the presence of LVI and PNI significantly reduced both OS and DFS. MLNR affected both DFS and OS. In ROC curve analysis, the cut-off value as 0.25 was accepted in keeping with the literature; and it revelated that MLNR greater than 0.25 significantly reduced both DFS and OS. All univariate analyses were given in Tables II and III.

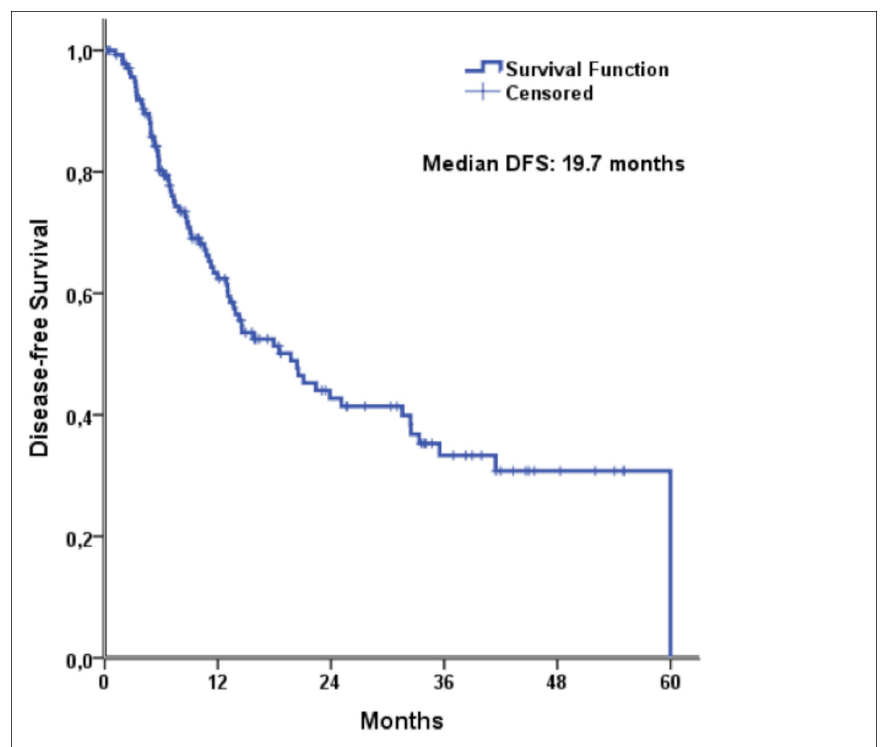

Figure 1-a: Disease-free survival curve.

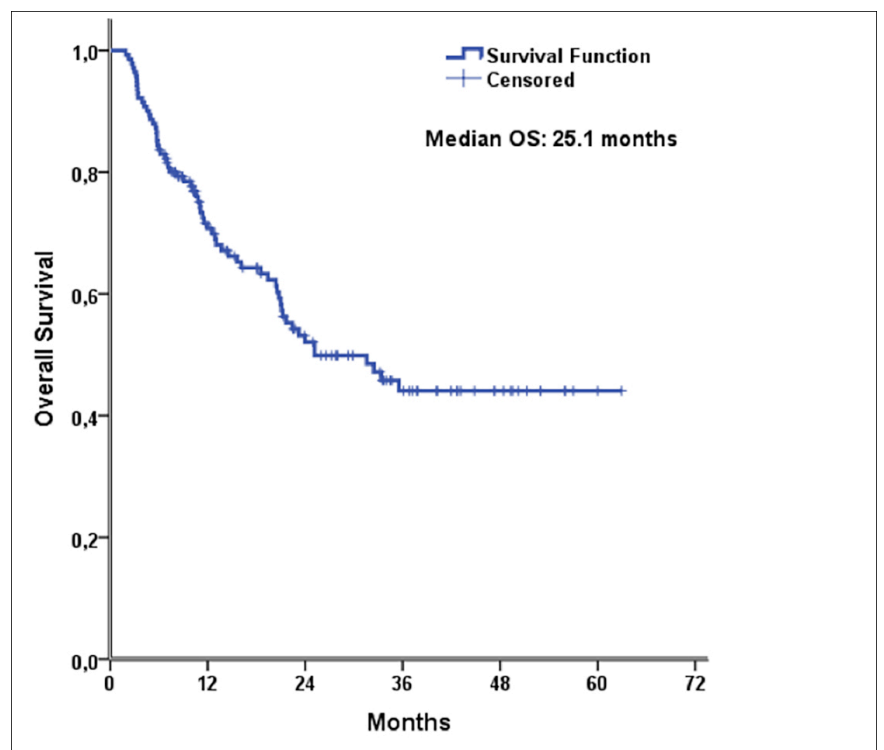

Figure 1-b: Overall survival curve.

The factors affecting DFS in univariate analysis were tumor stage of TNM, MNLR, PNI and LVI. Multivariable Cox regression analysis comprising those showed MLNR and PNI as independent factors for prognosis. Patients with MLNR $>0.25 \mathrm{had}$ a 2.39-fold higher risk of disease progression. The presence of PNI increased the risk of progression by 3.47 times. TNM stage was not a significant predictor of DFS. 
Table II: Factors affecting disease-free survival in univariate analysis.

\begin{tabular}{|c|c|c|c|}
\hline Characteristics & Median DFS & 95\% Confidence interval & p-value \\
\hline $\begin{array}{l}\text { Gender: } \\
\text { Female } \\
\text { Male }\end{array}$ & $\begin{array}{l}35.5 \\
15.8\end{array}$ & $\begin{array}{c}12.3-58.7 \\
9.2-22.4\end{array}$ & 0.249 \\
\hline $\begin{array}{l}\text { Age (years): } \\
\leq 60 \\
>60\end{array}$ & $\begin{array}{l}20.5 \\
17.9\end{array}$ & $\begin{array}{l}11.9-29.1 \\
8.2-27.6\end{array}$ & 0.168 \\
\hline $\begin{array}{l}\text { MLNR: } \\
\leq 0.25 \\
>0.25\end{array}$ & $\begin{array}{l}35.5 \\
8.8\end{array}$ & $\begin{array}{l}28.3-42.7 \\
4.8-12.9\end{array}$ & $<0.001$ \\
\hline $\begin{array}{l}\text { LVI: } \\
\text { Negative } \\
\text { Positive }\end{array}$ & $\begin{array}{l}32.5 \\
13.0\end{array}$ & $\begin{array}{l}19.6-45.3 \\
8.8-17.3\end{array}$ & 0.002 \\
\hline $\begin{array}{l}\text { PNI: } \\
\text { Negative } \\
\text { Positive }\end{array}$ & $\begin{array}{l}60.0 \\
11.5\end{array}$ & $\begin{array}{l}\text { NA } \\
7.1-16.0\end{array}$ & $<0.001$ \\
\hline $\begin{array}{l}\text { Differentiation: } \\
\text { Not poorly } \\
\text { Poorly }\end{array}$ & $\begin{array}{l}17.9 \\
20.5\end{array}$ & $\begin{array}{l}11.2-24.7 \\
11.2-29.9\end{array}$ & 0.756 \\
\hline $\begin{array}{l}\text { Stage: } \\
\text { Early } \\
\text { Advanced }\end{array}$ & $\begin{array}{l}60.0 \\
13.0\end{array}$ & $\begin{array}{l}\text { NA } \\
10.1-16.0\end{array}$ & $<0.001$ \\
\hline $\begin{array}{l}\text { Adjuvant treatment: } \\
\text { Received } \\
\text { Not received }\end{array}$ & $\begin{array}{l}18.5 \\
20.5\end{array}$ & $\begin{array}{l}12.2-24.8 \\
0.0-51.2\end{array}$ & 0.778 \\
\hline
\end{tabular}

Table III: Factors affecting overall survival in univariate analyses.

\begin{tabular}{|c|c|c|c|}
\hline Characteristics & Median OS & 95\% Confidence interval & p-value \\
\hline $\begin{array}{l}\text { Gender: } \\
\text { Female } \\
\text { Male }\end{array}$ & $\begin{array}{l}N R \\
24.0\end{array}$ & $\begin{array}{l}\text { NA } \\
13.2-34.8\end{array}$ & 0.353 \\
\hline $\begin{array}{l}\text { Age (years): } \\
\leq 60 \\
>60\end{array}$ & $\begin{array}{l}\text { NR } \\
23.2\end{array}$ & $\begin{array}{l}\text { NA } \\
11.2-35.3\end{array}$ & 0.032 \\
\hline $\begin{array}{l}\text { MLNR } \\
\leq 0.25 \\
>0.25\end{array}$ & $\begin{array}{l}\text { NR } \\
11.9\end{array}$ & $\begin{array}{l}\text { NA } \\
6.6-17.4\end{array}$ & $<0.001$ \\
\hline $\begin{array}{l}\text { LVI } \\
\text { Negative } \\
\text { Positive }\end{array}$ & $\begin{array}{l}35.5 \\
20.5\end{array}$ & $\begin{array}{l}\text { NA } \\
12.1-29.0\end{array}$ & 0.033 \\
\hline $\begin{array}{l}\text { PNI } \\
\text { Negative } \\
\text { Positive }\end{array}$ & $\begin{array}{l}\text { NR } \\
19.4\end{array}$ & $\begin{array}{l}\text { NA } \\
11.7-27.1\end{array}$ & $<0.001$ \\
\hline $\begin{array}{l}\text { Differentiation } \\
\text { Not poorly } \\
\text { Poorly }\end{array}$ & $\begin{array}{l}23.2 \\
35.5 \\
\end{array}$ & $\begin{array}{l}18.6-27.9 \\
\text { NA }\end{array}$ & 0.423 \\
\hline $\begin{array}{l}\text { Stage } \\
\text { Early } \\
\text { Advanced }\end{array}$ & $\begin{array}{l}\text { NR } \\
18.5\end{array}$ & $\begin{array}{l}\text { NA } \\
11.6-25.5\end{array}$ & $<0.001$ \\
\hline $\begin{array}{l}\text { Adjuvant treatment } \\
\text { Received } \\
\text { Not received }\end{array}$ & $\begin{array}{l}24.0 \\
32.5 \\
\end{array}$ & $\begin{array}{l}\text { NA } \\
16.8-48.1\end{array}$ & 0.912 \\
\hline
\end{tabular}

The factors affecting OS in univariate analyses were MLNR, LVI, PNI, advanced tumor stage, and advanced age ( $>60$ years). In multivariate Cox regression analysis, advanced age and MLNR remained independent poor prognostic factors for OS. Patients with MLNR $>0.25$ had a 3.76 -fold higher risk of shorter OS.
The most notable findings of this present study were that MLNR was an independent predictor of progression-free and overall survival in operated gastric cancer patients. When the cut-off label was taken as $>0.25$, MLNR showed a 2.39-fold higher risk of disease progression and 3.76-fold higher risk of shorter survival.

Adequate staging is vital in predicting prognosis in gastric 
cancer patients. ${ }^{4,5}$ The minimum number of lymph nodes required for adequate staging is accepted as $15 .^{19,20}$ Inadequate lymph node dissection leads to inadequate evaluation of prognosis. ${ }^{10}$ Studies have shown that the higher the number of lymph node examination after gastrectomy, the better the survival. ${ }^{20}$ MLNR was suggested as a reliable and reproducible method for prognostication as well as reducing the phenomenon of stage migration. ${ }^{10}$

In this study, patients were staged according to the TNM staging system and categorised as advanced stage (stage III $a-b-c)$ and early stage (stage I-II) disease. TNM staging appeared not a significant predictor of the overall survival of advanced stage patients. In addition, TNM stage was not a significant predictor of DFS, either. On the other hand, MLNR significantly predicted both survival parameters and was found as an independent prognostic factor. This study showed the prognostic effect of MLNR as more effective than TNM staging, in agreement with the previous studies.

No unanimous consensus has been reached regarding the cut-off value of MLNR in the prevailing studies. ${ }^{9,21}$ In some studies, evaluations were made according to whether the lymph node was negative or positive, and the ratio of negative lymph node and positive lymph node was evaluated..$^{10}$ In the study conducted by Hu et al., the cut-off value for the appropriate sensitivity and specificity limit was determined as 0.25 , similar to this study. ${ }^{1}$ In the later study, MLNR cutoff value was taken as 0.25 ; and MLNR together with other prognostic factors were examined. In multivariate analyses, advanced age, stage III and MLNR ( $>0.25$ ) were independent poor prognostic factors for OS. In terms of DFS, stage III and MLNR (>0.25) were found as independent prognostic factors. ${ }^{1}$ In this study, the cut-off value of MLNR was 0.25; similarly, as an important prognostic factor for both OS and DFS. In contrast, several cut-off categories of MLNR were used in other studies with comparable analyses additionally. ${ }^{8-10,18}$

Lymphovascular invasion and PNI are well-known prognostic factors. ${ }^{22,23}$ Therefore, these factors can guide to decide adjuvant treatment for early-stage gastric cancer. ${ }^{24}$ In this study, in multivariate analysis, PNI was found as an independent prognostic factor for DFS. Similar to This study, Bilici et al. showed that in patients with N3 gastric cancer who underwent curative resection MLNR above 0.75 , tumor differentiation and LVI were independent prognostic factors for DFS. ${ }^{4}$

It is essential to evaluate the high-risk patient in terms of recurrence potential and to determine which patient would benefit from adjuvant treatment. ${ }^{18} \mathrm{Kim}$ and colleagues evaluated the survival benefit of MLNR in 719 patients with gastric adenocarcinoma, who underwent curative-intent resection. The authors divided the study population into three groups with two cut-off values; 0.10 and 0.25 . Considering the prognostic factors; gastroesophageal junction tumor, T stage, LVI, and MLNR greater than 0.25 were independent predictors of survival. Besides, patients with MLNR $>0.25$ were shown to benefit from adjuvant chemoradiotherapy. ${ }^{18}$ In this study, the survival advantage was evident in patients with MLNR $>0.25$ and with advanced stage. The difference in the present study was that the association between MLNR and adjuvant therapy was not evaluated as a predictive effect of MLNR. In addition, receiving adjuvant therapy did not provide a significant difference in univariate analyses.

In another study, the MLNR evaluated as a prognostic factor and advanced age (>65), tumor size $(>10 \mathrm{~cm})$ and MLNR $(\geq 0.4)$ were shown to be independent prognostic factors in operated gastric cancer patients with pathologic N3. ${ }^{25}$ The differences from this study were inclusion of patients in all stages, not evaluating tumor size, and accepted different cut-off values.

Some limitations of this study are worthy to mention. First, the sample size was small and the follow-up period was relatively short. Second, it would be better if different staging system on prognosis such as TNM and Japanese classification of gastric carcinoma could be compared. ${ }^{16}$ Third, the lymph node negativity could not be evaluated independently, which needed a larger sample size.

\section{CONCLUSION}

In the current study, it was shown that the presence of $M L N R<0.25$ prolongs the DFS time and provides survival advantage regardless of TNM stages. MLNR is useful as an independent prognostic factor predicting survival, even better than TNM staging system.

\section{ETHICAL APPROVAL:}

The study was approved by the Ethics Committee of the Health Sciences University, Yildirim Beyazit Diskapi Training and Research Hospital (No. 77-17-2019).

\section{PATIENTS' CONSENT:}

Informed consents were obtained from all participants or their family, included in the study.

\section{CONFLICT OF INTEREST:}

Authors declared no conflict of interest.

\section{AUTHORS' CONTRIBUTION:}

ST: Substantial contributions to conception and design, acquisition of data, interpretation of data, and reviewed the paper.

FBB: Analysis and interpretation of data, drafting of manuscript, advices and final approval, and reviewed the paper.

\section{REFERENCES}

1. Hu M, Zhang S, Yang X, Shen Y, Li Z, Zhao Y, et al. The prognostic value of lymph node ratio for local advanced gastric cancer patients with adjuvant chemoradiotherapy after D2 
gastrectomy. Medicine (Baltimore) 2018; 97:e13079. doi: 10.1097/MD.0000000000013079.

2. Torre LA, Bray F, Siegel RL, Ferlay J, Lortet-Tieulent J, Jemal A. Global cancer statistics, 2012. CA Cancer J Clin. 2015; 65(2):87-108. doi.org/10.3322/caac.21262.

3. Zhao B, Zhang J, Zhang J, Luo R, Wang Z, Xu H, et al. Risk factors associated with lymph node metastasis for early gastric cancer patients who underwent non-curative endoscopic resection: A systematic review and meta-analysis. J Gastrointest Surg 2019; 23(7): 1318-28. doi: 10.1007/ s11605-018-3924-5.

4. Bilici A, Selcukbiricik F, Seker M, Oven BB, Olmez OF, Yildiz O, et al. Prognostic significance of metastatic lymph node ratio in patients with pn3 gastric cancer who underwent curative gastrectomy. Oncol Res Treat 2019; 42(4):209-16. doi.org/10.1159/000496746.

5. Dicken BJ, Bigam DL, Cass C, Mackey JR, Joy AA, Hamilton SM. Gastric adenocarcinoma: Review and considerations for future directions. Ann Surg 2005; 241(1):27-39. doi: 10.1097/01.sla.0000149300.28588.23.

6. Yokota $T$, Ishiyama S, Saito $T$, Teshima S, Shimotsuma M, Yamauchi $\mathrm{H}$. Treatment strategy of limited surgery in the treatment guidelines for gastric cancer in Japan. Lancet Oncol 2003; 4(7):423-8. doi: 10.1016/s1470-2045(03) 01140-9.

7. Yamashita K, Hosoda K, Ema A, Watanabe M. Lymph node ratio as a novel and simple prognostic factor in advanced gastric cancer. Eur J Surg Oncol 2016; 42(9):1253-60. doi: 10.1016/j.ejso.2016.03.001.

8. Ding YB, Chen GY, Xia JG, Zang XW, Yang HY, Yang L, et al. Correlation of tumor-positive ratio and number of perigastric lymph nodes with prognosis of patients with surgically-removed gastric carcinoma. World J Gastroenterol 2004; 10(2):182-5. doi: 10.3748/wjg.v10.i2.182.

9. Bademler $S$, Üçüncü MZ, Bulut T, Asoğlu O. Mide kanseri prognozunda metastatik lenf nodu oranı (Nratio) TNM Sınıflamasından. Bağımsız Bir Parametredir 2019; 15(1).

10. Yamashita H, Deng J, Liang H, Seto Y. Re-evaluating the prognostic validity of the negative to positive lymph node ratio in node-positive gastric cancer patients. Surgery 2017; 161(6):1588-96. doi: 10.1016/j.surg.2016.12.018.

11. Inoue $K$, Nakane $Y$, liyama $H$, Sato $M$, Kanbara $T$, Nakai $K$, et al. The superiority of ratio-based lymph node staging in gastric carcinoma. Ann Surg Oncol 2002; 9(1):27-34. doi: 10.1245/aso.2002.9.1.27.

12. Crew KD, Neugut Al. Epidemiology of upper gastrointestinal malignancies. Semin Oncol 2004; 31(4):450-64. doi: 10.1053/ j.seminoncol.2004.04.021.

13. Persiani R, Rausei S, Biondi A, Boccia S, Cananzi F, D'Ugo D. Ratio of metastatic lymph nodes: impact on staging and survival of gastric cancer. Eur J Surg Oncol 2008; 34(5):
519-24. doi: 10.1016/j.ejso.2007.05.009.

14. Sano T, Katai H, Sasako M, Maruyama K. Gastric lymphography and detection of sentinel nodes. Recent Results Cancer Res 2000; 157: 253-8. doi: 10.1007/978-3-642- 57151-0_22.

15. Yamashita K, Sakuramoto S, Watanabe M. Genomic and epigenetic profiles of gastric cancer: Potential diagnostic and therapeutic applications. Surg Today 2011; 41(1): 24-38. doi: 10.1007/s00595-010-4370-5.

16. Edge SB, Byrd DR, Carducci MA, Compton CC, Fritz A, Greene F. AJCC cancer staging manual Springer New York 2010.

17. Yamashita K, Ooki A, Sakuramoto S, Kikuchi S, Katada N, Kobayashi N, et al. Lymph node metastasis density (ND)-factor association with malignant degree and ND40 as "noncurative factor" in gastric cancer. Anticancer Res 2008; 28(1B):435-41.

18. Kim $Y$, Squires $M H$, Poultsides GA, Fields RC, Weber SM, Votanopoulos $\mathrm{KI}$, et al. Impact of lymph node ratio in selecting patients with resected gastric cancer for adjuvant therapy. Surgery 2017; 162(2):285-94. doi: 10.1016/j.surg.2017.03.023.

19. Roder JD, Bottcher K, Busch R, Wittekind C, Hermanek P, Siewert JR. Classification of regional lymph node metastasis from gastric carcinoma. German gastric cancer study group. Cancer 1998; 82(4):621-31.

20. Smith DD, Schwarz RR, Schwarz RE. Impact of total lymph node count on staging and survival after gastrectomy for gastric cancer: data from a large US-population database. J Clin Oncol 2005; 23(28):7114-24.

21. Xu DZ, Geng QR, Long ZJ, Zhan YQ, Li W, Zhou ZW, et al. Positive lymph node ratio is an independent prognostic factor in gastric cancer after $\mathrm{d} 2$ resection regardless of the examined number of lymph nodes. Annals of surgical oncology 2009; 16(2):319-26. doi: 10.1245/s10434- 008-0240-4.

22. Shang L, Li B, He F, Li Y, Li J, Zhao Q, et al. Effect of lymphatic vascular invasion on the prognosis of stage I [gastric cancer patients after radical gastrectomy]. Zhonghua Wei Chang Wai Ke Za Zhi 2018; 21(2):175-9.

23. Deng J, You Q, Gao Y, Yu Q, Zhao P, Zheng Y, et al. Prognostic value of perineural invasion in gastric cancer: A systematic review and meta-analysis. PLoS One 2014; 9(2): e88907. doi: 10.1371/journal.pone.0088907.

24. Du C, Zhou Y, Huang K, Zhao G, Fu H, Shi Y. Defining a high-risk subgroup of pathological T2NO gastric cancer by prognostic risk stratification for adjuvant therapy. J Gastrointest Surg 2011; 15(12):2153-8. doi: 10.1007/s11605-011- 1684-6.

25. Komatsu S, Ichikawa D, Miyamae M, Kosuga T, Okamoto K, Arita $T$, et al. Positive lymph node ratio as an indicator of prognosis and local tumor clearance in N3 gastric cancer. J Gastrointest Surg 2016; 20(9):1565-71. doi: 10.1007/ s11605- 016-3197-9. 